\title{
EVALUASI TINGKAT POLUTAN DARI KEGIATAN PENGELOLAAN SAMPAH DI RUMAH KOMPOS SRIKANA DAN KEPUTRAN KOTA SURABAYA
}

Irma Nur Asifah, Imam Thohari, Waluyo Jati

\begin{abstract}
Garbage materials are able to contaminate the environment in three ways: physically, chemically, and biologically. The large composition of garbage require management and processing to reduce garbage load entering the TPA. In relation to this, Dinas Kebersihan dan Pertamanan Kota Surabaya has initiated composting of organic wastes partly to reduce their volume. This study was aimed at measuring pollutants in compost materials especially in terms of $\mathrm{CO}, \mathrm{SO}_{2}$, and $\mathrm{H}_{2} \mathrm{~S}$ parameters. This activity was carried out in Composting Houses of Srikana and Keputran Surabaya.

This descriptive study was performed by measuring $\mathrm{CO}, \mathrm{SO}_{2}$, and $\mathrm{H}_{2} \mathrm{~S}$ and laboratory examination. The population under study was composting houses (18 sites) and the sample size was 2 composting houses.

Results showed that pollutant level of $\mathrm{CO}, \mathrm{SO}_{2}$ and $\mathrm{H}_{2} \mathrm{~S}$ in the air was not exceeding the quality standard being implemented in East Java. The CO level in Srikana Composting House was $4.21\left(\mu \mathrm{g} / \mathrm{Nm}^{3}\right)$ and in residential area was $3.37\left(\mu \mathrm{g} / \mathrm{Nm}^{3}\right) . \mathrm{SO}_{2}$ level in composting house was $12.04\left(\mu \mathrm{g} / \mathrm{Nm}^{3}\right)$, while outside of house of $16.71\left(\mu \mathrm{g} / \mathrm{Nm}^{3}\right)$ and in residential area was $4.16\left(\mu \mathrm{g} / \mathrm{Nm}^{3}\right)$. The $\mathrm{H}_{2} \mathrm{~S}$ level in composting house was $9.13\left(\mu \mathrm{g} / \mathrm{Nm}^{3}\right)$, outside the house was $6.54\left(\mu \mathrm{g} / \mathrm{Nm}^{3}\right)$ and in residential area was $3.22\left(\mu \mathrm{g} / \mathrm{Nm}^{3}\right)$. The CO level in Keputran Composting House was $9.66\left(\mu \mathrm{g} / \mathrm{Nm}^{3}\right)$, in outside of the house was $15,74\left(\mu \mathrm{g} / \mathrm{Nm}^{3}\right)$ and in the surrounding market was $4.18\left(\mu \mathrm{g} / \mathrm{Nm}^{3}\right)$. The $\mathrm{SO}_{2}$ level in composting house was 6,88 $\left(\mu \mathrm{g} / \mathrm{Nm}^{3}\right)$, outside of compost house $19.38\left(\mu \mathrm{g} / \mathrm{Nm}^{3}\right)$, and in the surrounding market was 2,76 $\left(\mu \mathrm{g} / \mathrm{Nm}^{3}\right) . \mathrm{H}_{2} \mathrm{~S}$ level in composting house was $16,14\left(\mu \mathrm{g} / \mathrm{Nm}^{3}\right)$, in outside of the house was $4,49\left(\mu \mathrm{g} / \mathrm{Nm}^{3}\right)$ and in the surrounding market was $1.97\left(\mu \mathrm{g} / \mathrm{Nm}^{3}\right)$. Temperature, humidity, and wind velocity laso have some influence as well but not too significant to increase pollutant level.

It is suggested to Dinas Kebersihan dan Pertamanan Kota Surabaya to add composting house in its list of air pollution monitoring station.
\end{abstract}

\section{PENDAHULUAN \\ Latar Belakang}

Sampah tidak dapat dipisahkan dari kehidupan manusia. Sampah dapat mencemari lingkungan dalam tiga cara yaitu secara fisik, kimia dan biologi. Secara fisik sampah dapat mengotori lingkungan, tidak estetik, menimbulkan bau yang tidak sedap, dan dapat menimbulkan sarang lalat atau tikus yang erat kaitannya dengan proses penularan penyakit (Sarudji, D 2006:281-282)

Komposisi sampah yang begitu besar, memerlukan suatu pengelolaan dan pengolahan untuk mengurangi beban sampah yang masuk ke dalam TPA. Terkait dengan hal tersebut, Dinas Kebersihan dan Pertamanan Kota Surabaya melakukan kegiatan pengomposan untuk pengolahan sampah organik, meminimalisir dari pembuangan sampah.
Kegiatan pengomposan di Rumah Kompos dilakukan secara aerob, dimana proses pengomposan berlangsung dalam keadaan di udara terbuka karena membutuhkan oksigen. Dalam hal ini, udara bebas harus bersentuhan langsung dengan bahan baku kompos yang berupa sampah organik. Pada proses penguraian zat organik dan proses dekomposisi pada proses aerob dapat menghasilkan gas seperti Amonia, Asam amino, $\mathrm{H}_{2} \mathrm{~S}, \mathrm{CH}_{4}$, $\mathrm{CO}, \mathrm{H}_{2}$, Alkohol, Asam organik, Fenol. Gas $\mathrm{NO}_{x} \mathrm{SO}_{2}$ merupakan gas yang dihasilkan akibat kegiatan manusia, gas ini dipakai sebagai indikator lain. Efek yang ditimbulkan yaitu dapat meningkatkan angka kesakitan dan kematian pada manusia, flora dan fauna dari pencemaran gas tersebut. Oleh karena itu, pengelolaan sampah dengan cara pengomposan mulai mendapat banyak perhatian guna 
mengurangi dampak negatif yang mungkin ditimbulkan.

\section{Pembatasan Masalah}

Analisis tingkat polutan udara dengan parameter $\mathrm{CO}, \mathrm{SO}_{2}$ dan $\mathrm{H}_{2} \mathrm{~S}$ yang dihasilkan dari kegiatan pengomposan di rumah kompos yaitu Rumah Kompos Srikana dan Rumah Kompos Keputran Kota Surabaya.

\section{Rumusan Masalah}

Berapa besar tingkat polutan udara yang dihasilkan dari kegiatan pengomposan di Rumah Kompos Srikana dan Rumah Kompos Keputran Kota Surabaya ditinjau melalui parameter $\mathrm{CO}, \mathrm{SO}_{2}$ dan $\mathrm{H}_{2} \mathrm{~S}$.

\section{Tujuan Penelitian}

Untuk mengetahui tingkat polutan yang dihasilkan dari kegiatan pengomposan di Rumah Kompos Srikana dan Rumah Kompos Keputran Kota Surabaya.

\section{METODE PENELITIAN}

\section{Jenis Penelitian}

Jenis penelitian yang dilakukan adalah penelitian deskriptif, yaitu suatu metode penelitian yang dilakukan untuk menggambarkan tentang proses pengomposan yang dapat menghasilkan gas polutan di Rumah Kompos Srikana dan Keputran Surabaya.

\section{Lokasi dan Waktu Penelitian}

Penelitian dilaksanakan pada Rumah Kompos Srikana dan Keputran Kota Surabaya dan dilaksanakan pada bulan Mei 2013.
Populasi dan Sampel

Berdasarkan data yang diperoleh dari Dinas Kebersihan dan Pertamanan Kota Surabaya maka populasi yang didapatkan sebanyak 18 Rumah Kompos. Sedangkan dari hasil penentuan sampel menggunakan teknik purposive sampling, sampel diperoleh sebanyak 2 rumah kompos.

\section{Teknik Pengumpulan Data}

1. Observasi : yaitu pengamatan langsung terhadap keadaan lokasi (Rumah Kompos Srikana dan Keputran).

2. Pengukuran : yaitu untuk mendapatkan hasil mengenai suhu, kelembaban, kecepatan angin, serta pengukuran kadar $\mathrm{CO}, \mathrm{SO}_{2}, \mathrm{H}_{2} \mathrm{~S}$ di lokasi.

3. Pemeriksaan Laboratorium : yaitu untuk mendapatkan hasil kadar $\mathrm{CO}$, $\mathrm{SO}_{2}, \mathrm{H}_{2} \mathrm{~S}$.

\section{Teknik Analisis Data}

Menggambarkan tentang proses pengomposan yang dapat menghasilkan gas polutan di Rumah Kompos Srikana dan Keputran Surabaya yang didapatkan dari pemeriksaan laboratorium dianalisis secara deskriptif dengan dibandingkan dengan standart Peraturan Gubernur Jawa Timur Nomor 10 Tahun 2009 Tentang Baku Mutu Udara Ambien Dan Emisi Sumber Tidak Bergerak Di Jawa Timur, untuk menggambarkan besar polutan yang terjadi. Kemudian disajikan dalam bentuk tabel.

\section{HASIL PENELITIAN DAN PEMBAHASAN}

1. Tingkat polutan yang dihasilkan dari pengolahan sampah di Rumah Kompos Srikana Surabaya

a. Hasil pemeriksaan tingkat polutan $\mathrm{CO}$

Tabel 1

HASIL PEMERIKSAAN TINGKAT POLUTAN CO DI RUMAH KOMPOS SRIKANA TAHUN 2013

\begin{tabular}{ccccc}
\hline No. & \multicolumn{1}{c}{$\begin{array}{c}\text { Lokasi Pengambilan } \\
\text { Sampel }\end{array}$} & $\begin{array}{c}\mathrm{CO} \\
\left(\mu \mathrm{g} / \mathrm{Nm}^{3}\right)\end{array}$ & $\begin{array}{c}\text { Baku Mutu CO } \\
\left(\mu \mathrm{g} / \mathrm{Nm}^{3}\right)\end{array}$ & $\begin{array}{c}\text { Kriteria } \\
(\mathrm{MS} / \mathrm{TMS})\end{array}$ \\
\hline 1. & Di rumah kompos & 4,21 & & $\mathrm{MS}$ \\
2. & Di luar rumah Kompos & 11,87 & 22,600 & $\mathrm{MS}$ \\
3. & Di pemukiman warga & 3,37 & & $\mathrm{MS}$ \\
\hline
\end{tabular}

Sumber: Data primer hasil pemeriksaan laboratorium 17 Mei 2013

Keterangan :

MS : Memenuhi Standart

TMS : Tidak Memenuhi Standart 
Dari tabel. 1 di atas dapat diketahui bahwa tingkat polutan $\mathrm{CO}$ di udara pada pengambilan sampel, di rumah kompos, di luar rumah kompos dan di pemukiman warga dekat dengan rumah kompos Srikana di bawah baku mutu menurut

b. Hasil pemeriksaan tingkat polutan $\mathrm{SO}_{2}$
Peraturan Gubernur Jawa Timur Nomor 10 Tahun 2009 Tentang Baku Mutu Udara Ambien Dan Emisi Sumber Tidak Bergerak Di Jawa Timur dengan batas maksimal $22,600\left(\mu \mathrm{g} / \mathrm{Nm}^{3}\right)$.

Tabel. 2

HASIL PEMERIKSAAN TINGKAT POLUTAN SO ${ }_{2}$ DI RUMAH KOMPOS SRIKANA TAHUN 2013

\begin{tabular}{clccc}
\hline No. & Lokasi Pengambilan Sampel & $\begin{array}{c}\mathrm{SO}_{2} \\
\left(\mu \mathrm{g} / \mathrm{Nm}^{3}\right)\end{array}$ & $\begin{array}{c}\mathrm{Baku} \mathrm{Mutu} \mathrm{SO}_{2} \\
\left(\mu \mathrm{g} / \mathrm{Nm}^{3}\right)\end{array}$ & $\begin{array}{c}\text { Kriteria } \\
(\mathrm{MS} / \mathrm{TMS})\end{array}$ \\
\hline 1. & Di rumah kompos & 12,04 & & $\mathrm{MS}$ \\
2. & Di luar rumah kompos & 16,71 & 262 & $\mathrm{MS}$ \\
3. & Di pemukiman warga & 4,16 & & $\mathrm{MS}$ \\
\hline
\end{tabular}

Sumber : Data primer hasil pemeriksaan laboratorium 17 Mei 2013

\section{Keterangan : \\ MS : Memenuhi Standart \\ TMS : Tidak Memenuhi Standart}

Dari table. 2 di atas dapat diketahui bahwa tingkat polutan $\mathrm{SO}_{2}$ di udara pada pengambilan sampel, di rumah kompos, di luar rumah kompos dan di pemukiman warga dekat dengan rumah kompos Srikana di bawah baku mutu menurut

c. Hasil pemeriksaan tingkat polutan $\mathrm{H}_{2} \mathrm{~S}$
Peraturan Gubernur Jawa Timur Nomor 10 Tahun 2009 Tentang Baku Mutu Udara Ambien Dan Emisi Sumber Tidak Bergerak Di Jawa Timur dengan batas maksimal 262 $\left(\mu \mathrm{g} / \mathrm{Nm}^{3}\right)$.

HASIL PEMERIKSAA TINGKAT POLUTAN $\mathrm{H}_{2}$ S DI RUMAH KOMPOS SRIKANA

Tabel. 3 TAHUN 2013

\begin{tabular}{clccc}
\hline No. & Lokasi Pengambilan Sampel & $\begin{array}{c}\mathrm{H}_{2} \mathrm{~S} \\
\left(\mu \mathrm{g} / \mathrm{Nm}^{3}\right)\end{array}$ & $\begin{array}{c}\text { Baku Mutu } \mathrm{H}_{2} \mathrm{~S} \\
\left(\mu \mathrm{g} / \mathrm{Nm}^{3}\right)\end{array}$ & $\begin{array}{c}\text { Kriteria } \\
(\mathrm{MS} / \mathrm{TMS})\end{array}$ \\
\hline 1. & Di rumah kompos & 9,13 & & $\mathrm{MS}$ \\
2. & Di luar rumah kompos & 6,54 & 42 & $\mathrm{MS}$ \\
3. & Di pemukiman warga & 3,22 & & $\mathrm{MS}$ \\
\hline
\end{tabular}

Sumber : Data primer hasil pemeriksaan laboratorium 17 Mei 2013

Keterangan

MS : Memenuhi Standart

TMS : Tidak Memenuhi Standart

Dari tabel. 3 di atas dapat diketahui bahwa tingkat polutan $\mathrm{H}_{2} \mathrm{~S}$ di udara pada pengambilan sampel, di rumah kompos, di luar rumah kompos dan di pemukiman warga dekat dengan rumah kompos Srikana di bawah baku mutu menurut
Peraturan Gubernur Jawa Timur Nomor 10 Tahun 2009 Tentang Baku Mutu Udara Ambien Dan Emisi Sumber Tidak Bergerak Di Jawa Timur dengan batas maksimal maksimal $42\left(\mu \mathrm{g} / \mathrm{Nm}^{3}\right)$. 


\section{Tingkat polutan yang dihasilkan dari pengolahan sampah di Rumah Kompos Keputran Surabaya}

a. Hasil pemeriksaan tingkat polutan $\mathrm{CO}$

Tabel. 4

HASIL PEMERIKSAAN TINGKAT POLUTAN CO DI RUMAH KOMPOS KEPUTRAN TAHUN 2013

\begin{tabular}{clccc}
\hline No. & Lokasi Pengambilan Sampel & $\begin{array}{c}\mathrm{CO} \\
\left(\mu \mathrm{g} / \mathrm{Nm}^{3}\right)\end{array}$ & $\begin{array}{c}\text { Baku Mutu CO } \\
\left(\mu \mathrm{g} / \mathrm{Nm}^{3}\right)\end{array}$ & $\begin{array}{c}\text { Kriteria } \\
(\mathrm{MS} / \mathrm{TMS})\end{array}$ \\
\hline 1. & Di rumah kompos & 9,66 & & $\mathrm{MS}$ \\
2. & Di luar rumah kompos & 15,74 & 22,600 & $\mathrm{MS}$ \\
3. & Di warga pasar & 4,18 & & $\mathrm{MS}$ \\
\hline
\end{tabular}

Sumber : Data primer hasil pemeriksaan laboratorium 17 Mei 2013

Keterangan

MS : Memenuhi Standart

TMS : Tidak Memenuhi Standart

Dari table. 4 di atas dapat diketahui bahwa tingkat polutan $\mathrm{CO}$ di udara pada pengambilan sampel, di rumah kompos, di luar rumah kompos dan di warga pasar dekat dengan rumah kompos Keputran di bawah baku mutu menurut Peraturan

b. Hasil pemeriksaan tingkat polutan $\mathrm{SO}_{2}$
Gubernur Jawa Timur Nomor 10 Tahun 2009 Tentang Baku Mutu Udara Ambien Dan Emisi Sumber Tidak Bergerak Di Jawa Timur dengan batas maksimal maksimal $22,600\left(\mu \mathrm{g} / \mathrm{Nm}^{3}\right)$.

Tabel. 5

HASIL PEMERIKSAN TINGKAT POLUTAN $\mathrm{SO}_{2}$ DI RUMAH KOMPOS KEPUTRAN TAHUN 2013

\begin{tabular}{clccc}
\hline No. & Lokasi Pengambilan Sampel & $\begin{array}{c}\mathrm{SO}_{2} \\
\left(\mu \mathrm{g} / \mathrm{Nm}^{3}\right)\end{array}$ & $\begin{array}{c}\text { Baku Mutu } \mathrm{SO}_{2} \\
\left(\mu \mathrm{g} / \mathrm{Nm}^{3}\right)\end{array}$ & $\begin{array}{c}\text { Kriteria } \\
(\mathrm{MS} / \mathrm{TMS})\end{array}$ \\
\hline 1. & Di rumah kompos & 6,88 & & $\mathrm{MS}$ \\
2. & Di luar rumah kompos & 19,38 & 262 & $\mathrm{MS}$ \\
3. & Di warga pasar & 2,76 & & $\mathrm{MS}$ \\
\hline
\end{tabular}

Sumber : Data primer hasil pemeriksaan laboratorium 17 Mei 2013

Keterangan :

MS : Memenuhi Standart

TMS : Tidak Memenuhi Standart

Dari table. 5 di atas dapat diketahui bahwa tingkat polutan $\mathrm{SO}_{2}$ di udara pada pengambilan sampel, di rumah kompos, di luar rumah kompos dan di warga pasar dekat dengan rumah kompos Keputran di bawah baku mutu menurut Peraturan
Gubernur Jawa Timur Nomor 10 Tahun 2009 Tentang Baku Mutu Udara Ambien Dan Emisi Sumber Tidak Bergerak Di Jawa Timur dengan batas maksimal maksimal $262\left(\mu \mathrm{g} / \mathrm{Nm}^{3}\right)$. 
c. Hasil pemeriksaan tingkat polutan $\mathrm{H}_{2} \mathrm{~S}$

Tabel. 6

HASIL PEMERIKSAAN TINGKAT POLUTAN $\mathrm{H}_{2}$ S DI RUMAH KOMPOS KEPUTRAN TAHUN 2013

\begin{tabular}{clccc}
\hline No. & Lokasi Pengambilan Sampel & $\begin{array}{c}\mathrm{H}_{2} \mathrm{~S} \\
\left(\mu \mathrm{g} / \mathrm{Nm}^{3}\right)\end{array}$ & $\begin{array}{c}\text { Baku Mutu } \mathrm{H}_{2} \mathrm{~S} \\
\left(\mu \mathrm{g} / \mathrm{Nm}^{3}\right)\end{array}$ & $\begin{array}{c}\text { Kriteria } \\
(\mathrm{MS} / \mathrm{TMS})\end{array}$ \\
\hline 1. & Di rumah kompos & 16,14 & & $\mathrm{MS}$ \\
2. & Di luar rumah kompos & 4,49 & 42 & $\mathrm{MS}$ \\
3. & Di warga pasar & 1,97 & & $\mathrm{MS}$ \\
\hline
\end{tabular}

Sumber : Data primer hasil pemeriksaan laboratorium 17 Mei 2013

Keterangan :

MS : Memenuhi Standart

TMS : Tidak Memenuhi Standart

Dari table. 6 di atas dapat diketahui bahwa tingkat polutan $\mathrm{H}_{2} \mathrm{~S}$ di udara pada pengambilan sampel, di rumah kompos, di luar rumah kompos dan di warga pasar dekat dengan rumah kompos Keputran di bawah baku mutu menurut Peraturan

Gubernur Jawa Timur Nomor 10 Tahun 2009 Tentang Baku Mutu Udara Ambien Dan Emisi Sumber Tidak Bergerak Di Jawa Timur dengan batas maksimal maksimal 42 $\left(\mu \mathrm{g} / \mathrm{Nm}^{3}\right)$.

3. Pengukuran Suhu, Kelembaban dan Kecepatan angin pada Rumah Kompos Srikana Surabaya

Tabel. 7

HASIL PENGUKURAN SUHU, KELEMBABAN DAN KECEPATAN ANGIN DI RUMAH KOMPOS SRIKANA SURABAYA TAHUN 2013

\begin{tabular}{clccc}
\hline No. & Lokasi Pengambilan Sampel & $\begin{array}{c}\text { Suhu } \\
\left({ }^{\circ} \mathrm{C}\right)\end{array}$ & $\begin{array}{c}\text { Kelembaban } \\
(\%)\end{array}$ & $\begin{array}{c}\text { Kecepatan angin } \\
(\mathrm{m} / \mathrm{s})\end{array}$ \\
\hline 1. & Di rumah kompos & 30 & 70 & 0,24 \\
2. & Di luar rumah kompos & 32 & 64 & 0,52 \\
3. & Di pemukiman warga & 30 & 84 & 0,42 \\
\hline
\end{tabular}

Sumber : Data primer, hasil pengukuran pada tanggal 17 Mei 2013

Berdasarkan tabel. 7 dapat dilihat bahwa hasil pengukuran suhu, kelembaban dan kecepatan angin dilakukan pada tanggal 17
Mei 2013 di Rumah Kompos Srikana Surabaya pada setiap titik tidak sama.

4. Pengukuran Suhu, Kelembaban dan Kecepatan angin pada Rumah Kompos Keputran Surabaya

Tabel. 8

HASIL PENGUKURAN SUHU, KELEMBABAN DAN KECEPATAN DI RUMAH KOMPOS KEPUTRAN SURABAYA TAHUN 2013

\begin{tabular}{clccc}
\hline No. & Lokasi Pengambilan Sampel & $\begin{array}{c}\text { Suhu } \\
\left({ }^{\circ} \mathrm{C}\right)\end{array}$ & $\begin{array}{c}\text { Kelembaban } \\
(\%)\end{array}$ & $\begin{array}{c}\text { Kecepatan angin } \\
(\mathrm{m} / \mathrm{s})\end{array}$ \\
\hline 1. & Di rumah kompos & 30 & 54 & 0,17 \\
2. & Di luar rumah kompos & 32 & 60 & 0,39 \\
3. & Di warga pasar & 30 & 62 & 1,08 \\
\hline
\end{tabular}

Sumber : Data primer, hasil pengukuran pada tanggal 17 Mei 2013

Berdasarkan table. 8 dapat dilihat bahwa hasil pengukuran suhu, kelembaban dan kecepatan angin dilakukan pada tanggal 17 Mei 2013 di Rumah Kompos Keputran Surabaya pada setiap titik tidak sama. 


\section{KESIMPULAN DAN SARAN Kesimpulan}

1. Tingkat polutan $\mathrm{CO}$ di Rumah Kompos Srikana dan Keputran Kota Surabaya

a. Tingkat polutan $\mathrm{CO}$ di Rumah Kompos Srikana pada tanggal 17 Mei 2013 yaitu di rumah kompos sebesar $4,21\left(\mu \mathrm{g} / \mathrm{Nm}^{3}\right)$, di luar rumah kompos sebesar $11,87\left(\mu \mathrm{g} / \mathrm{Nm}^{3}\right)$, di pemukiman warga dekat dengan rumah kompos sebesar $3,37\left(\mu \mathrm{g} / \mathrm{Nm}^{3}\right)$ di bawah baku mutu menurut Peraturan Gubernur Jawa Timur Nomor 10 Tahun 2009 Tentang Baku Mutu Udara Ambien Dan Emisi Sumber Tidak Bergerak Di Jawa Timur yaitu maksimal $22,600\left(\mu \mathrm{g} / \mathrm{Nm}^{3}\right)$.

b. Tingkat polutan $\mathrm{CO}$ di Rumah Kompos Keputran pada tanggal 17 Mei 2013 yaitu di rumah kompos sebesar 9,66 $\left(\mu \mathrm{g} / \mathrm{Nm}^{3}\right)$, di luar rumah kompos sebesar $15,74\left(\mu \mathrm{g} / \mathrm{Nm}^{3}\right)$, di warga pasar dekat dengan rumah kompos sebesar $4,18\left(\mu \mathrm{g} / \mathrm{Nm}^{3}\right)$ di bawah baku mutu menurut Peraturan Gubernur Jawa Timur Nomor 10 Tahun 2009 Tentang Baku Mutu Udara Ambien Dan Emisi Sumber Tidak Bergerak Di Jawa Timur yaitu maksimal $22,600\left(\mu \mathrm{g} / \mathrm{Nm}^{3}\right)$.

2. Tingkat polutan $\mathrm{SO}_{2}$ di Rumah Kompos Srikana dan Keputran Kota Surabaya

a. Tingkat polutan $\mathrm{SO}_{2}$ di Rumah Kompos Srikana pada tanggal 17 Mei 2013 yaitu di rumah kompos sebesar $12,04\left(\mu \mathrm{g} / \mathrm{Nm}^{3}\right)$, di luar rumah kompos sebesar $16,71\left(\mu \mathrm{g} / \mathrm{Nm}^{3}\right)$, di pemukiman warga dekat dengan rumah kompos sebesar $4,16\left(\mu \mathrm{g} / \mathrm{Nm}^{3}\right)$ di bawah baku mutu menurut Peraturan Gubernur Jawa Timur Nomor 10 Tahun 2009 Tentang Baku Mutu Udara Ambien Dan Emisi Sumber Tidak Bergerak Di Jawa Timur yaitu maksimal $262\left(\mu \mathrm{g} / \mathrm{Nm}^{3}\right)$.

b. Tingkat polutan $\mathrm{SO}_{2}$ di Rumah Kompos Keputran pada tanggal 17 Mei 2013 yaitu di rumah kompos sebesar $6,88\left(\mu \mathrm{g} / \mathrm{Nm}^{3}\right)$, di luar rumah kompos sebesar $19,38\left(\mu \mathrm{g} / \mathrm{Nm}^{3}\right)$, di warga pasar dekat dengan rumah kompos sebesar $2,76\left(\mu \mathrm{g} / \mathrm{Nm}^{3}\right)$ di bawah baku mutu menurut Peraturan Gubernur Jawa Timur Nomor 10 Tahun 2009 Tentang Baku Mutu Udara Ambien Dan Emisi Sumber Tidak Bergerak Di Jawa Timur yaitu maksimal $262\left(\mu \mathrm{g} / \mathrm{Nm}^{3}\right)$.
3. Tingkat polutan $\mathrm{H}_{2} \mathrm{~S}$ di Rumah Kompos Srikana dan Keputran Kota Surabaya

a. Tingkat polutan $\mathrm{H}_{2} \mathrm{~S}$ di Rumah Kompos Srikana pada tanggal 17 Mei 2013 yaitu di rumah kompos sebesar $9,13\left(\mu \mathrm{g} / \mathrm{Nm}^{3}\right)$, di luar rumah kompos sebesar $6,54\left(\mu \mathrm{g} / \mathrm{Nm}^{3}\right)$, di pemukiman warga dekat dengan rumah kompos sebesar 3,22( $\left.\mu \mathrm{g} / \mathrm{Nm}^{3}\right)$ di bawah baku mutu menurut Peraturan Gubernur Jawa Timur Nomor 10 Tahun 2009 Tentang Baku Mutu Udara Ambien Dan Emisi Sumber Tidak Bergerak Di Jawa Timur yaitu maksimal $42\left(\mu \mathrm{g} / \mathrm{Nm}^{3}\right)$.

b. Tingkat polutan $\mathrm{H}_{2} \mathrm{~S}$ di Rumah Kompos Keputran pada tanggal 17 Mei 2013 yaitu di rumah kompos sebesar $16,14\left(\mu \mathrm{g} / \mathrm{Nm}^{3}\right)$, di luar rumah kompos sebesar $4,49\left(\mu \mathrm{g} / \mathrm{Nm}^{3}\right)$, di warga pasar dekat dengan rumah kompos sebesar $1,97\left(\mu \mathrm{g} / \mathrm{Nm}^{3}\right)$ di bawah baku mutu menurut Peraturan Gubernur Jawa Timur Nomor 10 Tahun 2009 Tentang Baku Mutu Udara Ambien Dan Emisi Sumber Tidak Bergerak Di Jawa Timur yaitu maksimal $42\left(\mu \mathrm{g} / \mathrm{Nm}^{3}\right)$.

4. Analisis tingkat polutan dari kegiatan pengomposan di Rumah Kompos yaitu Rumah Kompos Srikana dan Keputran dengan parameter $\mathrm{CO}, \mathrm{SO}_{2}$ dan $\mathrm{H}_{2} \mathrm{~S}$

Berdasarkan hasil pemeriksaan dan pengukuran yang dilakukan di Rumah Kompos Srikana dan Keputran Kota Surabaya pada tanggal 17 Mei 2013 diketahui bahwa tingkat polutan $\mathrm{CO}, \mathrm{SO}_{2}$, $\mathrm{H}_{2} \mathrm{~S}$ yang berada di udara tidak menjadikan polutan yang melebihi baku mutu sesuai persyaratan menurut Peraturan Gubernur Jawa Timur Nomor 10 Tahun 2009 Tentang Baku Mutu Udara Ambien Dan Emisi Sumber Tidak Bergerak Di Jawa Timur, CO maksimal 22,600 $\left(\mu \mathrm{g} / \mathrm{Nm}^{3}\right), \mathrm{SO}_{2}$ maksimal $262\left(\mu \mathrm{g} / \mathrm{Nm}^{3}\right)$, dan $\mathrm{H}_{2} \mathrm{~S}$ maksimal $42\left(\mu \mathrm{g} / \mathrm{Nm}^{3}\right)$.

Suhu, kelembaban dan kecepatan angin ikut berpengaruh pada kadar $\mathrm{CO}, \mathrm{SO}_{2}, \mathrm{H}_{2} \mathrm{~S}$ yang berada di udara dan penyebarannya. Namun, tidak besar pengaruhnya terhadap meningkatnya polutan.

\section{Saran}

1. Bagi Dinas Kebersihan dan Pertamanan Kota Surabaya

Untuk Dinas Kebersihan dan Pertamanan Kota Surabaya sebaiknya dilakukan 
monitoring pada rumah kompos yang dapat dilakukan secara berkala yang bisa dilakukan oleh Badan Lingkungan Hidup atau badan lain yang berwenang untuk memonitoring kegiatan yang dilakukan pada setiap rumah kompos.

2. Bagi Penanggung jawab rumah kompos

Penanggung jawab rumah kompos supaya mengingatkan secara tegas pada tenaga pengelolah kompos dapat menggunakan APD misalnya berupa masker, agar pada saat mengelola kompos polutannya tidak menimbulkan efek terhadap diri sendiri dan kesehatannya lebih terjaga.

3. Bagi Peneliti

Diharapkan peneliti dapat menambah ilmu pengetahuan, pengalaman dan dapat menerapkan ilmu yang sudah didapatkan pada bangku perkuliahan.

\section{DAFTAR PUSTAKA}

Chandra, B., 2006. Pengantar Kesehatan Lingkungan. Jakarta, Kedokteran EGC

Gubernur Jawa Timur., 2009. Peraturan Gubernur Jawa Timur Nomor 10 Tahun 2009 Tentang Baku Mutu Udara Ambien Dan Emisi Sumber Tidak Bergerak Di Jawa Timur. Surabaya

Habibi, L., Pembuatan Pupuk Kompos Dari Limbah Rumah Tangga. Bandung, Titian Imu.

Isroi., Yuliarti, N., 2009. Kompos. Yogyakarta, C.V Andi Offset.

Mukono., 2011. Aspek Kesehatan Pencemaran Udara. Surabaya, Pusat
Penerbitan dan Percetakan Universitas Airlangga.

Notoatmodjo, S., 2010. Metodologi Penelitian Kesehatan. Jakarta, Rineka Cipta.

Peraturan Pemerintah Republik Indonesia Nomor 41 Tahun 1999 Tentang Pengendalian Pencemaran Udara. Jakarta Poltekkes Kemenkes Surabaya Jurusan Kesehatan Lingkungan Surabaya. Pedoman Penulisan Karya Tulis IImiah 2011. Surabaya.

Sarudji, D., 2006. Kesehatan Lingkungan. Sidoarjo, Media IImu.

Sastrawijaya, T. A., 2009. Pencemaran Lingkungan. Jakarta, Rineka Cipta.

Surasri, S., Setiawan., 2005. Metodologi Penelitian. Surabaya. Percetakan Duatujuh.

Suryati, T., 2009. Bijak \& Cerdas Mengolah Sampah. Jakarta. Agromedia Pustaka.

Tim Penulis PS., 2008. Penanganan \& Pengolahan Sampah. Jakarta, Penebar Swadaya.

Undang-undang Republik Indonesia Nomor 18 Tahun 2008 Tentang Pengelolaan Sampah.

Wardhana, A. W., 2001. Dampak Pencemaran Lingkungan. Yogyakarta,Andi Offset.

Widyatmoko., Moerdjoko, S., 2002. Menghindari, mengolah dan menyingkirkan sampah. Jakarta, PT Dinastindo Adiperkasa Internasional. 